\title{
IMÁGENES DE SAN JOSÉ EN LA ESTIRPE ROLDÁN
}

\section{IMAGES OF SAN JOSÉ IN THE ROLDÁN LINEAGE}

\author{
JESÚs PORRES BENAVIDES \\ Universidad Rey Juan Carlos
}

Recibido: 16/05/2019 Aceptado: 04/12/2019

\section{RESUMEN}

La devoción a San José comienza de manera intensa a partir del final de la baja Edad Media. Se analizan en el presente artículo diferentes formas iconográficas de éste, sobre todo la de san José y el niño Jesus itinerante y san José con el niño en sus brazos. Estudiamos una serie de esculturas de carácter devocional de Pedro Roldan, su hija Luisa Ignacia, la Roldana y su nieto Pedro Duque Cornejo.

Palabras clave: Pedro Roldan, la Roldana, Pedro Duque Cornejo, escultura barroca.

\section{ABSTRACT}

Devotion to San José begins intensely after the end of the late Middle Ages. Different iconographic forms of this one are analyzed in the present article, especially that of Saint Joseph and the traveling Jesus child and Saint Joseph with the child in his arms. We studied a series of devotional sculptures by Pedro Roldan, his daughter Luisa Ignacia, la Roldana and his grandson Pedro Duque Cornejo.

Keywords: Pedro Roldan, la Roldana, Pedro Duque Cornejo, baroque sculpture. 
Como bien recuerda José Roda, tras siglos de casi indiferencia a la figura de San José, la devoción a este santo aparece con fuerza en el siglo XV gracias a algunos escritos ${ }^{1}$. Dentro de esta nueva corriente espiritual tuvo especial interés la devotio moderna que proponía una forma de vivir la religión más personal y animaba a meditar sobre la humanidad de Jesus y de María, su madre.

Al poner de relieve aquellos episodios de la infancia de Cristo, se empezó a destacar el papel de san José. Durante la Contrarreforma se va a desarrollar especialmente la devoción al esposo de María y numerosas órdenes religiosas propagaron su culto, como es el caso de la reforma carmelita de Santa Teresa de Jesús, que le dedicó el patronazgo o advocación de 12 de sus 17 nuevas fundaciones conventuales.

Creció el número de cofradías gremiales o devocionales que lo tuvieron como protector o patrón, como por ejemplo la de los carpinteros. De este modo, durante el siglo XVI aparecen las primeras representaciones de San José con el niño Jesús de manera individualizada. También en ese momento se recupera la iconografía del santo joven, de frondoso y ondulado cabello, acompañado de una profunda barba bífida y olvidando esas representaciones que se habían dado hasta la fecha, como un varón anciano que remarcaba la idea de la virginidad perpetua de Maria.

En determinados sermones, autos sacramentales y poesías encontramos a san José en contraste con María, su esposa, que era joven y hermosa, mientras que él era viejo y pobre. En ocasiones esta disparidad convirtió a san José en un personaje oscuro e incluso caricaturesco ${ }^{2}$. A partir de entonces aparecerá como un varón joven con unas facciones agradables. Se afianzan también ahora los atributos propios del santo como la vara florida de azucenas ${ }^{3}$.

1 RODA PEÑA, J., “A propósito de una escultura dieciochesca de San José”. Laboratorio de Arte, 5 (2), 1992, p. 369.

2 BURGOS ÁVILA, I., Estudio de la evolución iconográfica de san José, 2011, Link file://C:/Users/urjc/Downloads/San_Jose._Evolucion_iconografica.pdf, p.7.

3 Este atributo viene de la tradición, que según parece, se origina en los Evangelios apócrifos, donde se relata que fueron convocados al templo un hombre de cada tribu de Israel, para elegir un candidato para la Virgen María. José fue por la tribu de Judá. Cada hombre debía llevar una vara consigo, y estas fueron dejadas sobre el altar del templo. Cuando al día siguiente el sacerdote entró en el Sancta Sanctórum, un ángel tomó la vara más pequeña, la de José, y, según algunas versiones la vara floreció, y según otras la paloma del Espíritu Santo surgió de ella, señalando al varón que debería desposar a Maria. Así se cumpliría lo narrado por el Profeta Isaías: "Y saldrá una rama de la raíz de Jesse, y una flor saldrá de su raíz". (Is 11,1). Por otro lado este atributo es símbolo también de la castidad. 
Dentro de las Artes Plásticas, y en concreto en el ámbito de la escultura andaluza, se van a popularizar dos versiones ${ }^{4}$ : En una, san José sostiene al niño Jesús en su regazo con una mano y porta en la otra la vara de azucenas. Algunos teólogos han visto en esta imagen una prefiguración eucarística pues recuerda al "sacerdote que lleva entre sus manos a Cristo-Hostia". Es interesante como la literatura piadosa de la España barroca, refiriéndose al trato cariñoso entre padre e hijo recoge frases como "tomaba al niño en sus brazos y le traía cantando cantarcicos (..) gorjeabale, regalabale y dabales dijes como a niño"5.

Pedro Roldan hará una imagen de san José que le encarga el cabildo catedral de Sevilla en 1664. Supuestamente esta talla se convertirá rápidamente en un modelo a seguir para escultores como Antonio Gijón o Cristóbal Ramos ${ }^{6}$. Estamos de acuerdo con el profesor Pleguezuelo de que la imagen que se da como segura, actualmente en el museo catedralicio, no tiene la calidad que se supone a una obra en la que trabajaría en exclusiva Pedro Roldán, aunque estilísticamente esté en la órbita ${ }^{7}$.

Como bien recoge Catherine Hall - Van Den Elsen esta imagen a su vez inspira a otros iconos, incluso pictóricos como el que pintara Francisco Meneses Osorio en $1684^{8}$. Autores como el propio Pleguezuelo o Herrera García han puesto mayor atención en una imagen conservada en la actual capilla de San José del Sagrario catedralicio y que pudiera tratarse de la original de Roldan. Quizás se parte de la noticia dada en 1671 por Fernando de la Torre Farfán, quien describe una imagen de San José con el Niño en brazos que estaba situada en aquel momento en el retablo dedicado a éste, a los pies de la catedral y junto a la capilla de San Laureano ${ }^{9}$.

En la otra versión, San José y el niño están de pie en actitud itinerante, subrayándose esta idea del santo como protector de Jesús niño o guiando sus primeros pasos. Esta disposición en marcha es similar al grupo que representa

4 (Roda, 1992: 370).

5 GRACIAN DE LA MADRE DE DIOS, J., Josefina. excelencias de san José Esposo de la Virgen Maria (citado en Black, Charlene Villaseñor. Creating the cult of St. Joseph: Art and Gender in the spanish Empire, Princenton \& oxford, Princeton university Press, 2006, p.197, n 41.

$6 \quad$ Ídem 371.

7 PLEGUEZUELO HERNÁNDEZ, A., "Luisa Roldán en Sevilla y San José con el Niño Jesús: atribuciones e iconografía”. Laboratorio de arte, 29, 2017, pp. 377-396.

8 HALL - VAN DEN ELSEN, C., Fuerza e intimismo: Luisa Roldán, escultora (1652-1706) Consejo Superior de Investigaciones Científicas, Madrid, 2018, p.44.

9 Está claro que efectivamente Roldán inaugura un prototipo de San José con el niño Jesús en brazos que después desarrollarán autores durante el XVIII. Roda Peña identificó hace unos años el magnífico San José de Blas Molner, que proveniente de la parroquia de San Miguel de Sevilla, conserva hoy la hermandad de Pasión en su sede de la colegial del Divino Salvador, que sigue este modelo roldanesco. 
la Sagrada Familia como "Trinidad de la Tierra". Este tema, tan divulgado en los territorios de la monarquía hispánica durante la primera mitad del siglo XVII, va a pervivir en el siglo XVIII, pese a ser paulatinamente ensombrecida por la nueva modalidad, que presentaba al santo carpintero sosteniendo al Niño entre pañales. Muchos autores como Martínez Montañés, Juan de Mesa u Ocampo van a popularizar esta iconografía de San José y el niño caminantes.

Una obra josefina que debemos poner en la órbita de Roldán es la de tamaño natural existente en la iglesia de Santa Cruz de Sevilla en un pilar del lado de la epístola, catalogable dentro del círculo del taller de Roldán (Fig.1). En la misma zona, la de San José con el Niño, situada en la capilla sacramental de Santa María la Blanca (Fig.2), obra donada a la hermandad sacramental en 1677, según refiere el profesor Teodoro Falcón Márquez ${ }^{10}$. Esta última quizás se acerca más al estilo de su hija Luisa, sobre todo en la figura del niño Jesús. El santo de pie, iniciando la marcha con los pliegues de la túnica y el manto muy vaporosos, sostiene al niño entre sus brazos que juega con él.

10 Fue donada por Francisco Blanco, hermano de la Hermandad Sacramental, que además aportó tres doblones para la cera del retablo en la festividad del santo. Consta su nombre en la peana de la imagen, donde se puede leer: Este santo mandó hacer don Francisco Blanco y lo donó a la hermandad del Santísimo de Santa María la Blanca. Año 1677. FALCÓN MÁRQUEZ, T., La Iglesia de Santa María la Blanca y su entorno arte e historia, Editorial de la Universidad de Sevilla, 2015. Ha sido restaurada por Manuel Ballesteros Rodríguez y Alejandro Cascajares García en 2017. 

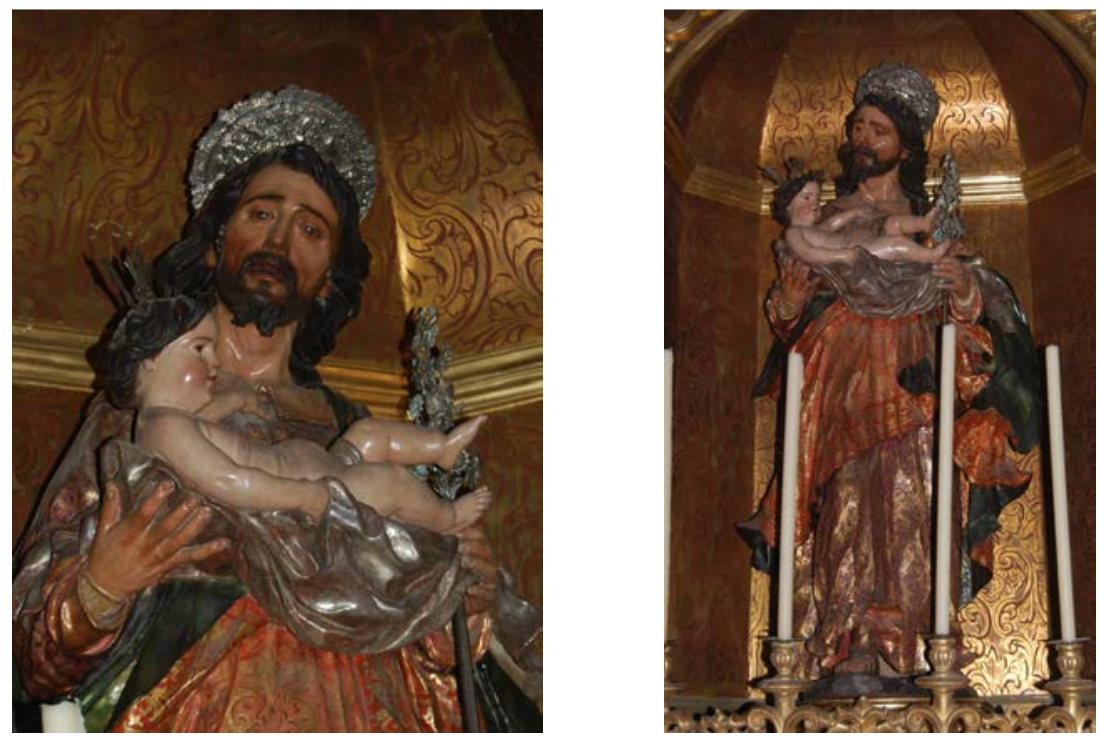

Figura 1: San José con el niño, taller de Pedro Roldán, 2ª mitad del XVII, iglesia de Santa Cruz (Sevilla).

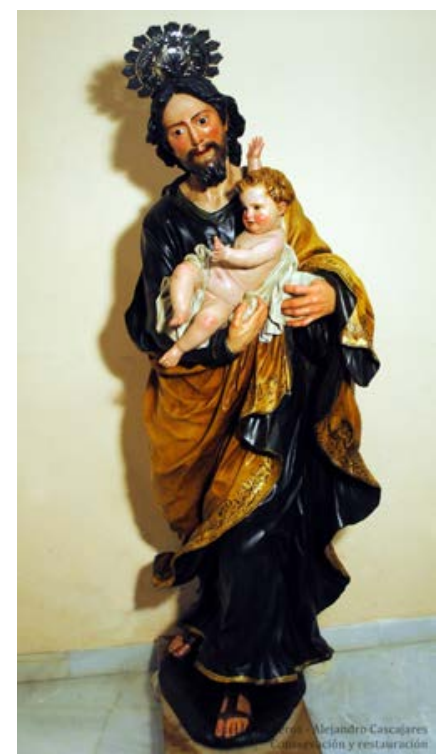

Figura 2: San José con el Niño, taller de Pedro Roldán, $2^{\mathrm{a}}$ mitad del XVII, iglesia de Santa María la Blanca (Sevilla). 
En los últimos tiempos se han encontrado diferentes imágenes de San José debidas a Luisa Ignacia Roldan, más conocida como la Roldana ${ }^{11}$ (Sevilla 1652-Madrid 1706), como, por ejemplo, la del convento de dominicas de Bormujos procedente del de Santa Catalina de Osuna. El profesor Herrera lo compara con otras obras como el San José o el San Antonio de la iglesia de San Antonio de Cádiz (c. 1687), cuyos niños Jesús tienen gran parecido.

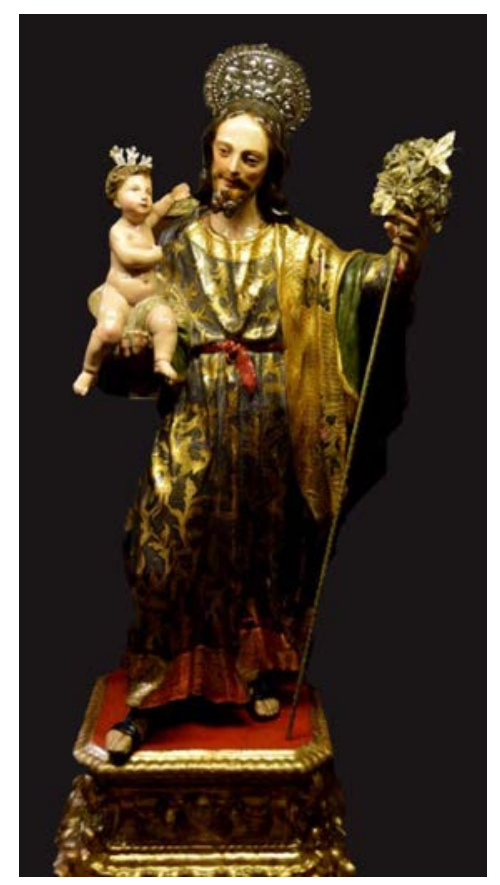

Figura 3: San José con el Niño, circulo de la Roldana, fines del XVIII, museo carmelita del Santo Ángel (Sevilla). (C) Carlos Peñuelas Jordán.

Como recuerda Herrera, ante la escasez de fuentes documentales, la metodología atribucionista funciona como instrumento para engrosar el corpus de la autora $^{12}$. En los últimos años se han realizado, en medios científicos, varias

11 HERRERA GARCÍA, F. J.; PÉREZ DE TENA, A. "Un San José atribuido a La Roldana en el Convento de Santa María la Real de Bormujos, Sevilla". Atrio: Revista de Historia del Arte, no 17 , 2011, pp. 59-68.

12 PLEGUEZUELO HERNÁNDEZ, A., "Luisa Roldán en Sevilla y San José con el Niño Jesús: atribuciones e iconografía". Laboratorio de arte, 29, 2017, pp. 377-396. Ver también MARTÍNEZ ALCALDE, J., "Una nueva obra para el catálogo de la Roldana”, Boletín de las Cofradías de Sevilla, 
atribuciones a la Roldana de imágenes de San José con el Niño de las que la mayoría han sido unánimemente aceptadas ${ }^{13}$, aunque con excepciones ${ }^{14}$. También se pueden estudiar imágenes de San José en pequeños belenes atribuidos y seguros de la Roldana ${ }^{15}$. Algunas son excepcionales como el San José en el convento de Nuestra Señora de Belén, en Antequera o el San José con el Niño del convento de San Antón (Granada).

En el museo carmelita del Santo Ángel de Sevilla, pero proveniente del convento de las Teresas de Écija hay una pequeña imagen de San José con el niño Jesus ${ }^{16}$ (fig.3) sostenido en el brazo derecho, mientras que con la otra sostiene la consabida vara de azucenas que también podría encuadrarse dentro de la producción de la escultora.

Presentamos también aquí una pequeña imagen inédita de san José de una colección particular sevillana ${ }^{17}$ (fig.4) que estilísticamente casa con la obra de la Roldana.

376, 1991, pp.44-45. Aquí da a conocer una pequeña imagen de San José en el museo diocesano de Salamanca.

13 PLEGUEZUELO HERNÁNDEZ, A., "Luisa Roldán en Sevilla ...op. cit., p. 378.

14 Así la pequeña imagen que presentó hace unos años María Victoria García Olloqui de un san José con el niño itinerante de una colección particular madrileña no responde ni a la calidad ni al estilo de la Roldana en GONZÁLEZ GÓMEZ, J. M. y MEJÍAS ÁLVAREZ, M. J. (coord.) LABORATORIO DE ARTE. 100 años de investigación del patrimonio artístico y cultural (1907-2007). Catálogo de la exposición celebrada en la Casa de la Provincia de Sevilla entre Julio y agosto de 2007. Diputación de Sevilla, 2007, pp.62-63.

15 GARCÍA OLLOQUI, M. V., "La iconografía de "la Natividad" en la obra de La Roldana. El problema de los belenes atribuidos. diferencias, estudio estilístico y opiniones cualificadas". Revista Fuentes $\mathrm{n}^{\circ} 1.2000$.

16 Hace pareja con una pequeña Inmaculada.

17 Las medidas son: peana: 46 x42, $17 \mathrm{~cm}$ alto, S. José: $27 \times 33,57 \mathrm{~cm}$ alto y el Niño Jesús: 16 x 16, $25 ' 5 \mathrm{~cm}$. de alto. Agradecemos a la restauradora Elena Rivero las informaciones aportadas de esta obra. 

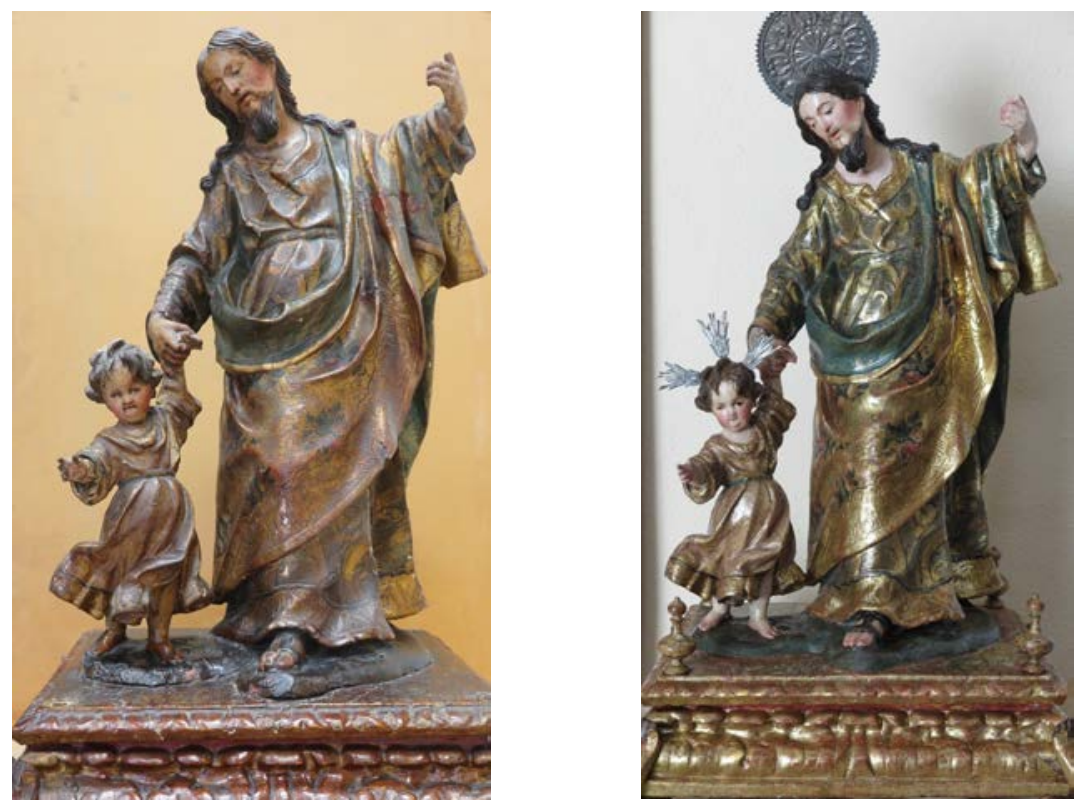

Figura 4: San José, circulo de la Roldana, fines del XVIII, colección particular (antes y después de la restauración). (C) Elena Rivero Osuna.

La imagen está en el primer tipo de iconografía que hemos comentado de San José itinerante que da la mano a su pequeño hijo que parece que inicia el caminar. El santo de pie activa dinámicamente la composición con el brazo izquierdo en alto sosteniendo la rama florecida, mientras la derecha sujeta de la mano a su hijo. El rostro del santo que mira cariñosamente a Jesús tiene una espesa barba y largos cabellos ondulados (fig.5).

El niño, a pesar de su pequeño tamaño, cuenta con un rostro muy jovial (fig.6) y con alborotados bucles de pelo que recuerdan a esculturas que se le atribuyen como la pequeña cabeza de san Juan Bautista niño, donación de González Abreu, que guarda el museo de Bellas Artes de Sevilla ${ }^{18}$ o las pequeñas cabecitas modeladas en barro como la del grupo de San Diego de Alcalá y la Virgen en el Victoria and Albert Museum de Londres.

18 Ver en PLEGUEZUELO HERNÁNDEZ, A., "Ternura, dolor y sonrisas. Los sentimientos en la obra de Luisa Roldán" En El triunfo del barroco en la escultura andaluza e hispanoamericana / coord. por Lázaro Gila Medina, Francisco Javier Herrera García, 2018, pp. 286-287 

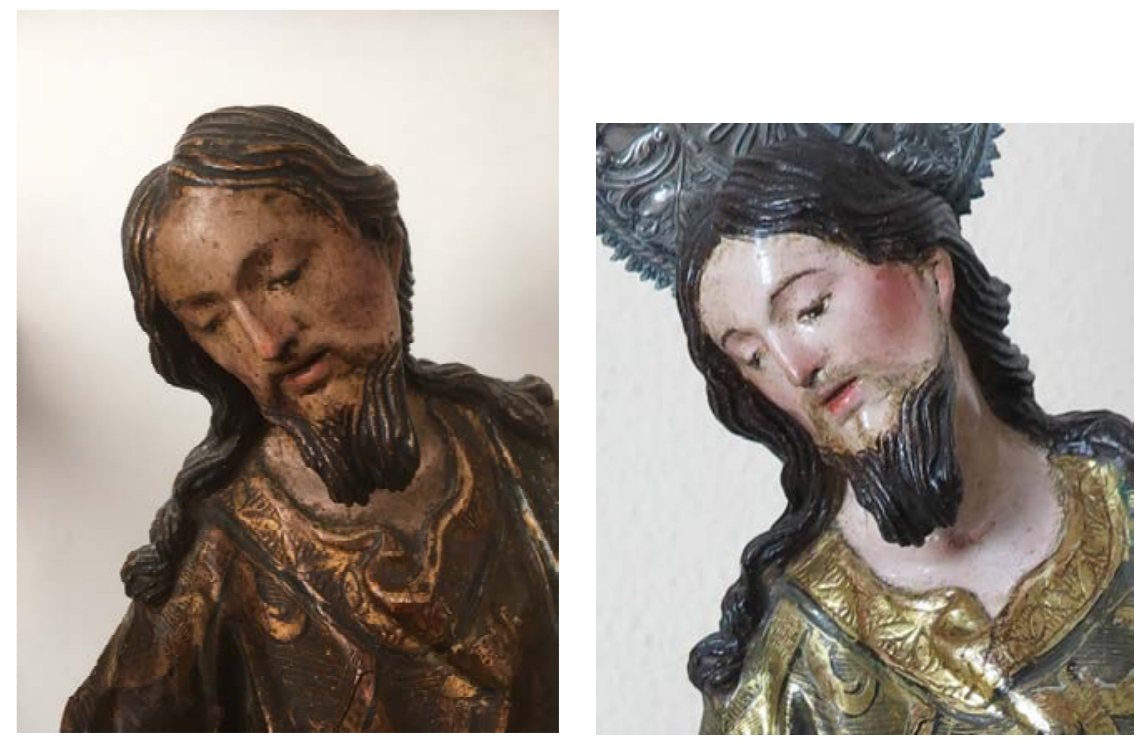

Figura 5: Detalle del rostro del San José (antes y después de la restauración). (C) Elena Rivero Osuna.
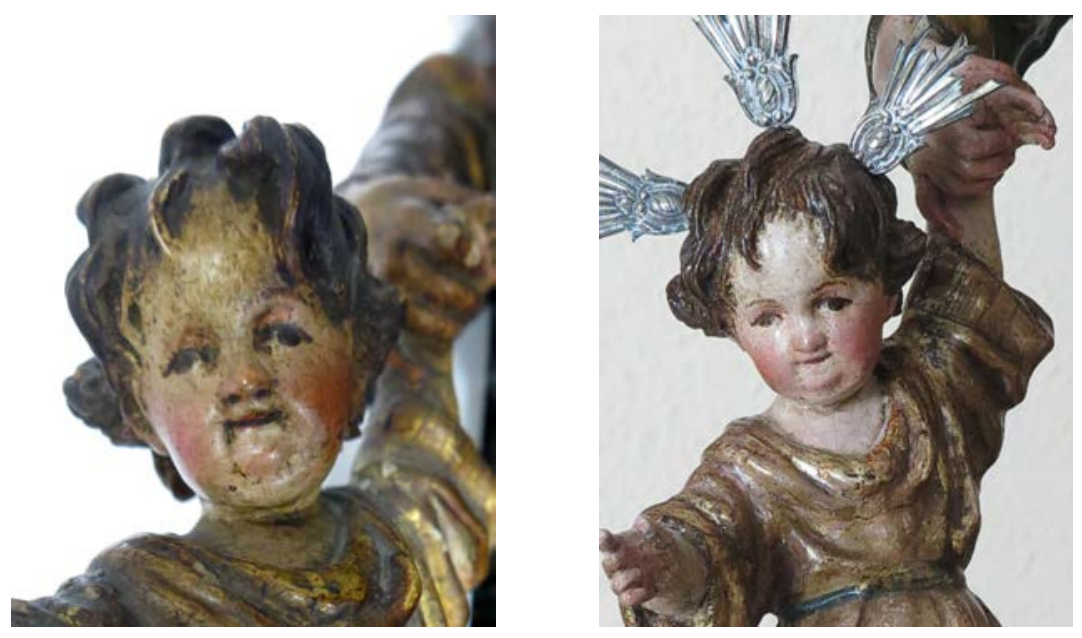

Figura 6: Detalle del rostro del niño (antes y después de la restauración). (C) Elena Rivero Osuna. 
Aunque quizás no tuvo el éxito de su hermana Luisa, también Maria se dedicó al ejercicio de la escultura junto con su marido Matías Brunenque. Moreno Arana ${ }^{19}$ ha atribuido una agradable imagen josefina al taller del matrimonio. La obra se encuentra en la parroquia del Carmen de La Muela, Algodonales (Cádiz), pero proviene del antiguo monasterio del Juncal. Como recuerda Moreno Arana, son artistas de "actividad poco conocida", pero con obras tan significativas como la imagineria del retablo mayor de la parroquia de las Nieves de Olivares (Sevilla).

La importancia de Pedro Duque Cornejo (1678-1757), tanto en la escultura andaluza como en la española, ha sido subrayada por numerosos autores que han estudiado su rica personalidad artística ${ }^{20}$. Parece ser que su infancia y adolescencia transcurrieron en el taller de su abuelo, el famoso Pedro Roldán, en el que su padre, el escultor José Felipe Duque Cornejo, y su madre, la pintora Francisca Roldán trabajaron. Pedro y su tía Luisa Ignacia fueron coetáneos, aunque este era más joven que La Roldana, pues vivió entre 1678 y 1757, por lo que pensamos que estaría más integrado en el Barroco dieciochesco que su tía, que vivió entre 1652 y $1706^{21}$.

En los últimos tiempos se están estudiando facetas más desconocidas del autor como la de dibujante. Manuel García Luque ha podido documentar entre sus obras un dibujo de San José con el niño, realizado con técnica de pluma y $\operatorname{aguada}^{22}$.

Como recuerda García Luque, el repertorio de imágenes de San José de Duque Cornejo demuestra la convivencia de las dos iconografías antes comentadas. Al grupo de san José itinerante pertenece el relieve que está en el retablo mayor de la capilla del palacio episcopal de Córdoba, y con anterioridad ya había tenido ocasión de afrontar el tema en dos grupos exentos, uno para la

19 MORENO ARANA, J. M., "Estudio Histórico- Artístico" en Imagineria recuperada estudio y restauración de un conjunto de esculturas de las parroquias de Algodonales, la Muela y Zahara de la Sierra. JIMÉNEZ LÓPEZ DE ENGUILETA, Javier E.(dir) Jerez de la Frontera, 2019, p. 86.

20 GARCÍA LUQUE, M., "Duque Cornejo, el último barroco" Ars magazine: revista de arte y coleccionismo, $\mathrm{N}^{\circ} .28,2015$, pp. 110-121.

21 GARCÍA OLLOQUI, M. V. "Estudio sobre la autoría de tres Dolorosas andaluzas vinculadas a La Roldana, de discutida atribución" Espacio y Tiempo: Revista de Ciencias Humanas, $\mathrm{n}^{\circ} 24$, 2010, pp. 147-162.

22 Como recuerda García Luque, ninguna de las esculturas conocidas de Duque Cornejo encaja exactamente con este boceto. Aunque quizás esta hoja constituya, al menos, una primera idea o tanteo para el grupo de Marchena, pues tanto en el dibujo como en la escultura encontramos el peculiar detalle del canastillo sostenido por el Niño. 
hermandad de carpinteros del municipio de Marchena (1731-1732) y la Casa Cuna de Sevilla (1733-1734) ${ }^{23}$ realizados con escasos años de diferencia.

Traemos a colación una pequeña escultura del santo con el niño Jesús en madera policromada y dorada ${ }^{24}$ (fig.7). En esta escultura el avance de la pierna derecha y una marcada curvatura del torso hacia delante girándose hacia el Niño que sostiene el brazo izquierdo, proporciona un sentido dinámico a la composición.

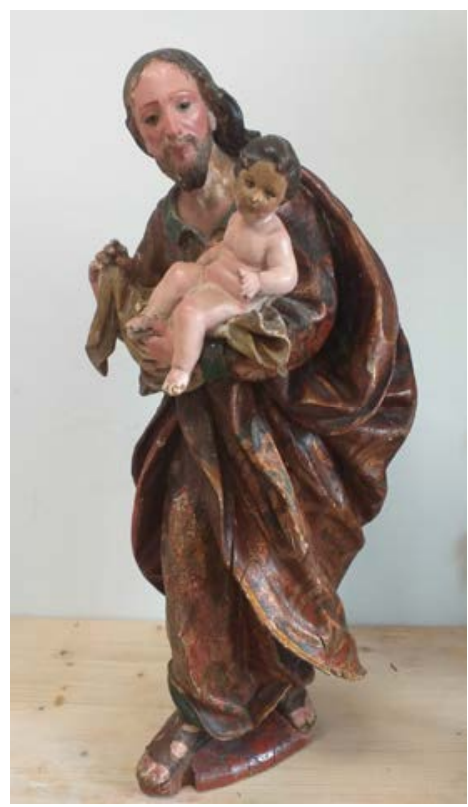

Figura 7: San José, Pedro Duque Cornejo, $1^{\mathrm{o}}$ tercio del siglo XVIII, colección particular.

Este sentido se acentúa con un cuidado estudio de los volúmenes de la capa y la túnica del santo, buscando los efectos vibrantes. El niño se presenta algo inclinado hacia la izquierda, favoreciendo así la visión de la cabeza de su padre, que lo mira con ternura, mientras con la mano derecha hace un ademán de levantar el pañal, quizás con la intención de tapar a su hijo.

La obra también se presenta muy dinámica en sus laterales (fig.8), especialmente el derecho, donde se aprecia el zigzag de la figura. Recuerda al San José de la capilla del palacio de San Telmo en Sevilla, algo menor del natural ${ }^{25}$ y quizás pudiera tratarse de un boceto previo, aunque lo más normal es considerarla simplemente como una imagen de devoción para algún particular o institución.

El niño se muestra algo volcado hacia la derecha, quizás un efecto armónico para que aparezca, en una visión frontal, la cabeza del padre a la izquierda. Con un bracito se agarra del pañal y el otro lo levanta. La imagen del santo en disposición de huso que frecuentemente dispone en alguna de sus imágenes con

23 GARCÍA LUQUE, M. "Dibujos de Duque Cornejo en el Álbum Jaffe (II): la colección del Hood Museum of Art”. Philostrato. Revista de Historia y Arte, no 4,2018, p.37.

24 Agradecemos a Pedro Franco las informaciones y fotografías aportadas de esta obra.

25 Mide $139 \times 60 \times 60 \mathrm{~cm}$. 
ese efecto zigzagueante, la reproduce, por ejemplo, en los evangelistas que realiza para la canastilla del paso del Santo Entierro de Écija.

En otras imágenes va a repetir Duque Cornejo esta iconografía como en la Cartuja del Paular de Madrid (fig.9) ${ }^{26}$ e imágenes que se le atribuyen como el pequeño San José que está en la iglesia de San Juan Bautista de Écija. Esta imagen de pequeñas dimensiones tiene un aspecto vaporoso, al estar sustentada en una nube con cabezas de querubines y la volatilidad de su manto, cuyos pliegues interiores se abren como si tuviera una entrada de aire bajo sus pies. A esto ayuda la propia cabellera del santo o la actitud de su hijo que soporta con su mano izquierda.

También es llamativo como esta tipología de San José se va a repetir en la misma localidad, como la que se encuentra en una hornacina rococó de la capilla del Cristo de San Gil, aunque quizás sin la calidad de la anterior. En la iglesia de la Merced de la misma localidad se encuentra otra imagen de San José (fig.10) de tamaño casi del natural con parecida disposición del anterior, aunque sin los efectos volátiles y quizás con la suma calidad que Duque imprimía a sus imágenes.

La peana tiene una inscripción que pone "se pinto y doro a devoción de el RF Joan Galeo religioso lego año de 1734" con lo cual apoya la posibilidad cronológica de que hubiera salido del taller del escultor.

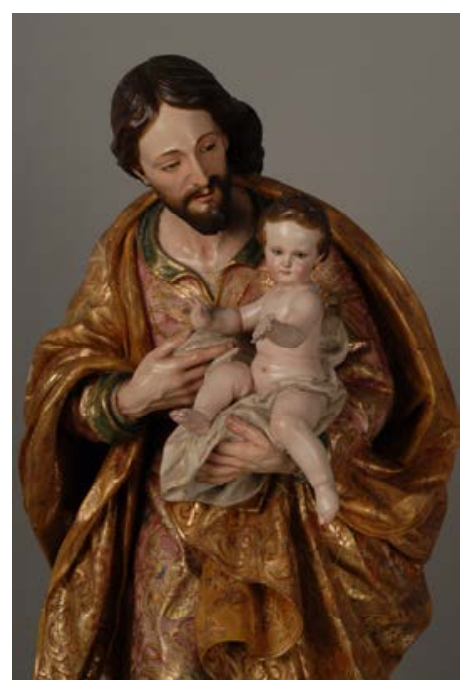

Figura 8: San José, Pedro Duque Cornejo, capilla del palacio de San Telmo (Sevilla). Fondo Gráfico Archivo IAPH. (Autor: Santos Madrid, José Manuel)"

26 Así en el año 2008 pude ver la magnífica imagen de San José con el niño que hace pareja con el San Rafael en la iglesia de Santo Domingo de Guzmán de la localidad gaditana de Bornos, atribuible a Duque Cornejo. En la tesis, aún sin publicar, de Manuel García Luque Pedro Duque Cornejo: Estudio de su vida y obra (1678-1757) Granada 2018.p.675-676, se estudia dicha obra. Otro San José de mayores proporciones salido del taller de Duque Cornejo es el que se encuentra en la iglesia de San Agustín de Osuna, atribuido por Rodríguez Buzón. García Luque, atinadamente, observa que es diferente del de la capilla de San Telmo y el realizado para la cartuja del Paular. Ídem 685. 


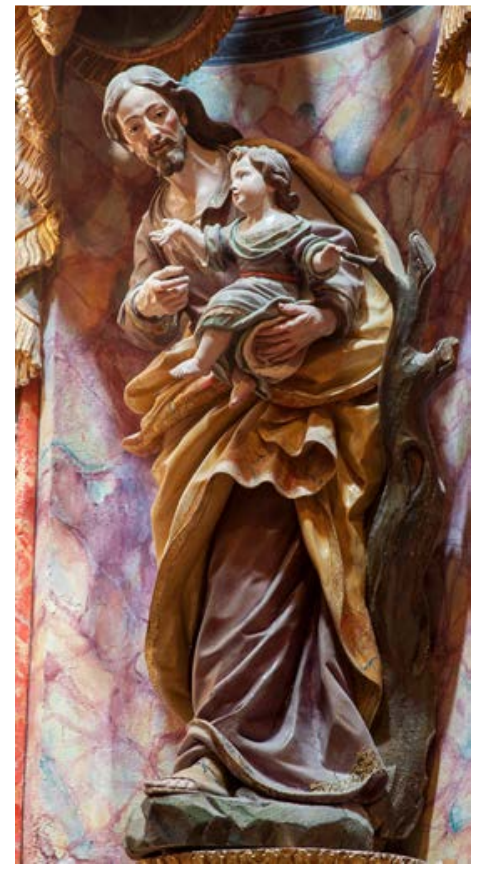

Figura 10: San José, Pedro Duque Cornejo, Cartuja del Paular de Madrid (C) Manuel García Luque.

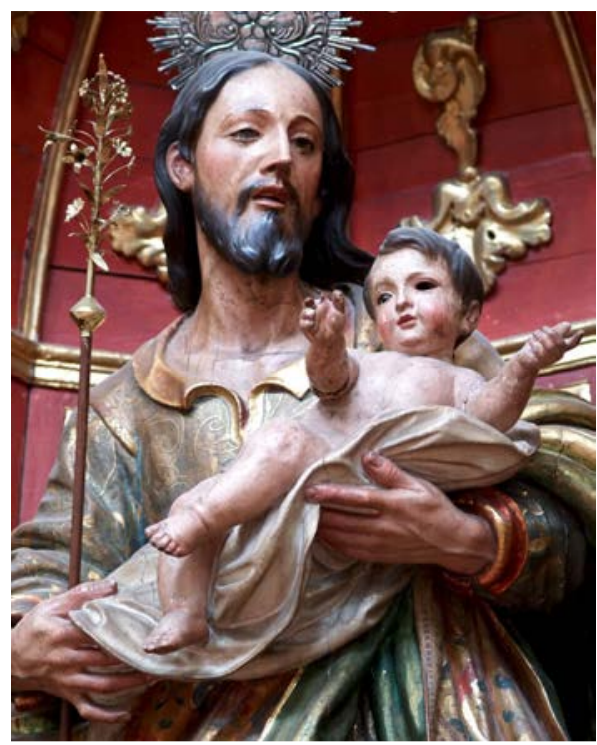

Figura 11: San José, Pedro Duque Cornejo, iglesia de la Merced, Écija (Sevilla). 


\section{BIBLIOGRAFÍA}

\section{BURGOS ÁVILA, I}

(2011) Estudio de la evolución iconográfica de san José. Link file:///C:/Users/urjc/Downloads/San_Jose._Evolucion_iconografica.pdf

FALCÓN MÁRQUEZ, T.

(2015): La Iglesia de Santa Maria la Blanca y su entorno arte e historia, Editorial de la Universidad de Sevilla.

GARCÍA LUQUE, $M$.

(2013): "Pedro Duque Cornejo y la escultura barroca en Sevilla: nuevas aportaciones". Cuadernos de Arte de la Universidad de Granada, no 44, pp. 5984.

(2015): "Duque Cornejo, el último barroco" Ars magazine: revista de arte y coleccionismo, $\mathrm{N}^{\mathrm{o}}$. 28, pp. 110-121.

(2018): "Dibujos de Duque Cornejo en el Álbum Jaffe (II): la colección del Hood Museum of Art". Philostrato. Revista de Historia y Arte, no 4, pp.3361.

(2018) Pedro Duque Cornejo: Estudio de su vida y obra (1678-1757). Tesis doctoral. Universidad de Granada.

GARCÍA OLLOQUI, M. V.

(2000): "La iconografía de "la Natividad" en la obra de La Roldana. El pro-

blema de los belenes atribuidos. diferencias, estudio estilístico y opiniones cualificadas. Revista Fuentes $\mathrm{n}^{\circ} 1$.

(2010): "Estudio sobre la autoría de tres Dolorosas andaluzas vinculadas a La Roldana, de discutida atribución" Espacio y Tiempo: Revista de Ciencias Humanas, $\mathrm{n}^{\circ}$ 24, pp. 147-162.

GONZÁLEZ GÓMEZ, J. M. y MEJÍAS ÁLVAREZ, M. J. (coord.)

(2007): LABORATORIO DE ARTE. 100 años de investigación del patrimonio artístico y cultural (1907-2007). Catálogo de la exposición celebrada en la Casa de la Provincia de Sevilla entre Julio y agosto de 2007. Diputación de Sevilla, pp.62-63.

GRACIAN DE LA MADRE DE DIOS, J.

Josefina. excelencias de san José Esposo de la Virgen Maria (citado en Black, Charlene Villaseñor. Creating the cult of St. Joseph: Art and Gender in the spanish Empire, Princenton \& oxford, Princeton university Press, 2006, n 41, p.197.

HALL - VAN DEN ELSEN, C.

(2018) Fuerza e intimismo: Luisa Roldán, escultora (1652-1706) Consejo Superior de Investigaciones Científicas, Madrid.

HERRERA GARCÍA, F. J.; PÉREZ DE TENA, A. 
(2011): "Un San José atribuido a La Roldana en el Convento de Santa María la Real de Bormujos, Sevilla". Atrio: Revista de Historia del Arte, $\mathrm{n}^{\mathrm{o}}$ 17, pp. 59-68.

PLEGUEZUELO HERNÁNDEZ, A.

(2017): "Luisa Roldán en Sevilla y San José con el Niño Jesús: atribuciones e iconografía". Laboratorio de arte, 29, pp. 377-396.

(2018): "Ternura, dolor y sonrisas. Los sentimientos en la obra de Luisa Roldán"

En El triunfo del barroco en la escultura andaluza e hispanoamericana / coord. por Lázaro Gila Medina, Francisco Javier Herrera García, pp. 267-288.

RODA PEÑA, J.

(1992): “A propósito de una escultura dieciochesca de San José”. Laboratorio de Arte, 5 (2), pp. 369-378.

\section{Jesús Porres Benavides}

Departamento Ciencias de la Educación, Lenguaje, Cultura y Artes, Ciencias Histórico-Jurídicas y Humanísticas y Lenguas Modernas. Universidad Rey Juan Carlos. Madrid, España. https://orcid.org/0000-0002-4042-7426 jesus.porres@urjc.es 
